\title{
Survival and spread of arctic plants in response to climate change: DNA-based evidence
}

\author{
Inger G. Alsos', M.E. Edwards ${ }^{1,2}$ and C.L. Clarke ${ }^{2}$

\begin{abstract}
Preserving biodiversity requires knowledge of the processes that underlie geographical patterns of species distribution and sustain diverse communities over long periods of time. Studies of modern and ancient DNA may
\end{abstract} \\ provide new insight into these processes.
}

The fate of the NW European biota during the last glacial period has been debated for almost 150 years. While the consensus in the 1960s was that at least the arctic-alpine elements of the flora survived in small, coastal, ice-free areas or on nunataks in Greenland, Iceland, Svalbard, or Fennoscandia, a more recent review concluded that all extant species colonized post-glacially (Brochmann et al. 2003).

These opposing views of arctic plant history are based on different perspectives on the frequency of long-distance dispersal, evolution rate, and species' ability to persist under a changing climate. Molecular tools have shed new light on this debate.

By analyzing genetic variation within present-day populations (modern DNA studies), the relationship among populations in different geographical areas can be established. Further, based on the amount and spatial structure of genetic diversity modern molecular data can also be used to infer areas of glacial persistence (i.e. where there is high genetic diversity and/or distinct genetic markers) and the direction of postglacial dispersal (Avise 2000). More recently, advances in the use of ancient DNA have greatly increased our ability to detect past species' distributions and responses to climate changes.

\section{Lessons learned from studies of modern DNA}

Studies of modern DNA have greatly advanced our knowledge of past dispersal. For example, genetic fingerprinting of 17 widespread arctic plant species throughout their current distributional range showed that the main barriers to dispersal were the Ural Mountains, the Greenland Ice Sheet, and the Atlantic Ocean, plus the lowland areas between the Alps and the Scandinavian Mountains (Eidesen et al. 2013). Alsos et al. (2015) extended the dataset to 25 species and used this in combination with floristic studies to infer the main dispersal routes in the north Atlantic region (Fig. 1).

\section{These data show that long-distance} (300-1000 km) dispersal in this region was frequent. In contrast, long-term isolation and evolution, as indicated by unique genotypes and high levels of genetic diversity for some species in some areas, appears to have been uncommon. Thus, current data indicate that postglacial dispersal may have been extensive while glacial survival was rare (Alsos et al. 2015; Westergaard et al. 2019). However, studies of modern DNA only give a relative age of past events and may overlook processes such as extinction of lineages or repeated dispersal. Recent advances in ancient sedimentary DNA have great potential to fill this knowledge gap (Parducci et al. 2017).

Combining modern DNA data with species distributions may enable an estimation of genetic consequences of climate change on arctic plants in the past (Pellissier et al. 2016) and projection of future scenarios (Alsos et al. 2012). Past changes in species' ranges were associated with a genetic bottleneck effect: a shift in species' distribution by 1000 $\mathrm{km}$ is associated with an average loss of $21 \%$ of the genetic diversity. All species, even common ones, are expected to lose part of their current range as a consequence of ongoing global warming. This range loss is expected to cause loss of genetic diversity, with herbs lacking berries or other adaptations for long-distance dispersal being especially at risk.

\section{What can we learn from} studies of ancient DNA?

Ancient DNA can provide direct evidence for the occurrence of a plant species at a given site and time in the past and thus greatly improve our ability to reconstruct past glacial refugia and dispersal routes. While past presence of a given species may be indicated by the presence of macrofossils (e.g. Binney et al. 2009), arctic-alpine plant species are often poorly represented due to variable preservation; furthermore, they are often under-represented in pollen records because the majority of taxa are insect-pollinated, having poor pollen productivity and transport characteristics (Birks, 2008).

Calibration studies have demonstrated that sediment DNA comes from within the local catchment area (Alsos et al. 2018) and that pollen is not likely to be a source of sediment DNA (Sjögren et al. 2017). Ancient DNA extracted from sediments (sedaDNA) has proven a useful new tool for reconstructing past plant community composition, particularly with regard to arctic-alpine herbs (Willerslev et al. 2014), and it can significantly augment information derived from pollen and plant macrofossil records (Alsos et al. 2016; Parducci et al. 2017).

In a recent study of a long $(24 \mathrm{~m})$ sediment core from Lake Bolshoye Shchuchye in the Polar Ural Mountains of Arctic Russia, Clarke et al. (2019) assessed how the diversity of the arctic-alpine flora fared through largemagnitude climate changes over the past 24,000 years using sedaDNA analysis. The lake catchment has supported a typical arctic-alpine community over the last 24,000 years, while there has also been diversification through time to include shrub-tundra and boreal-forest taxa (Fig. 2).

The sedaDNA record provides robust empirical evidence of the persistence of the arctic-alpine flora through a long period of environmental change, including the postglacial expansion of woody taxa and

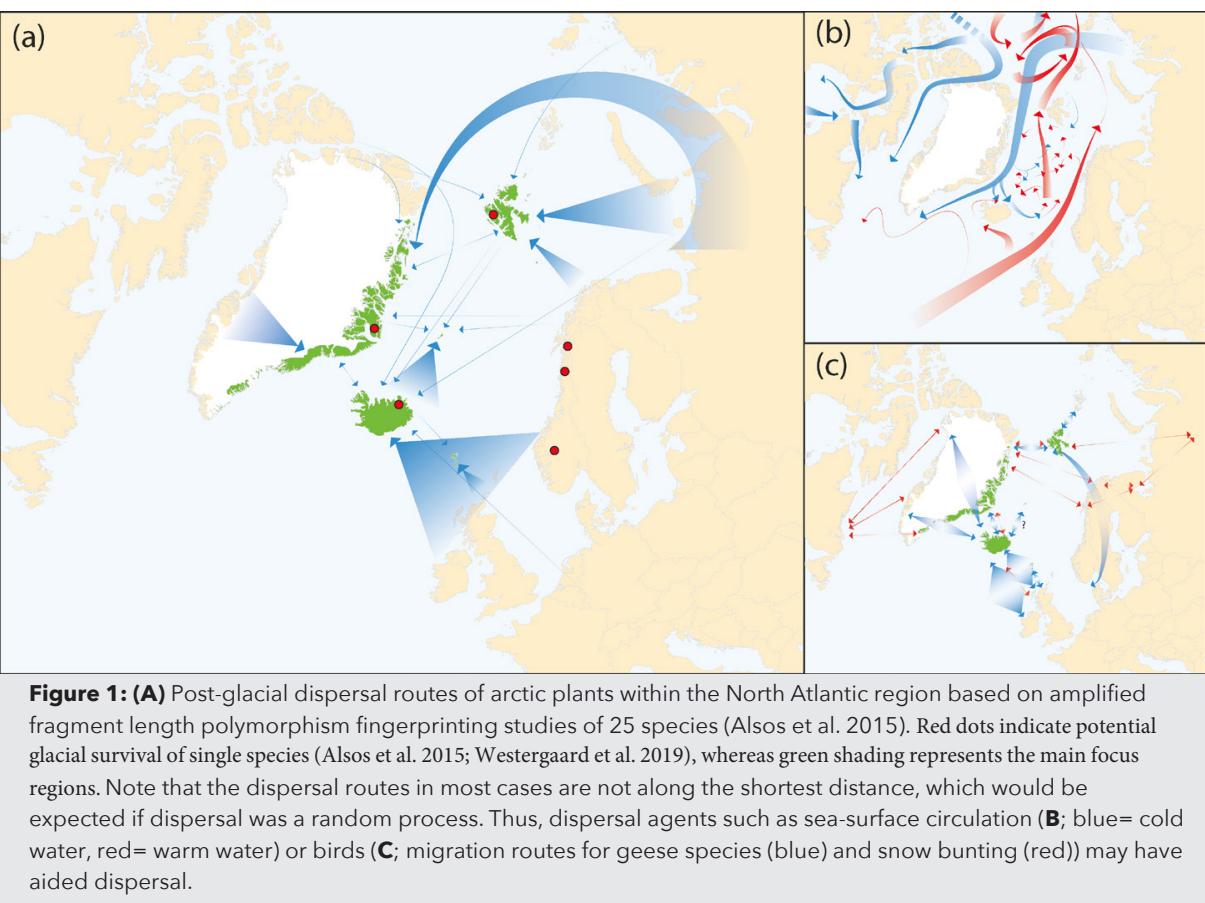




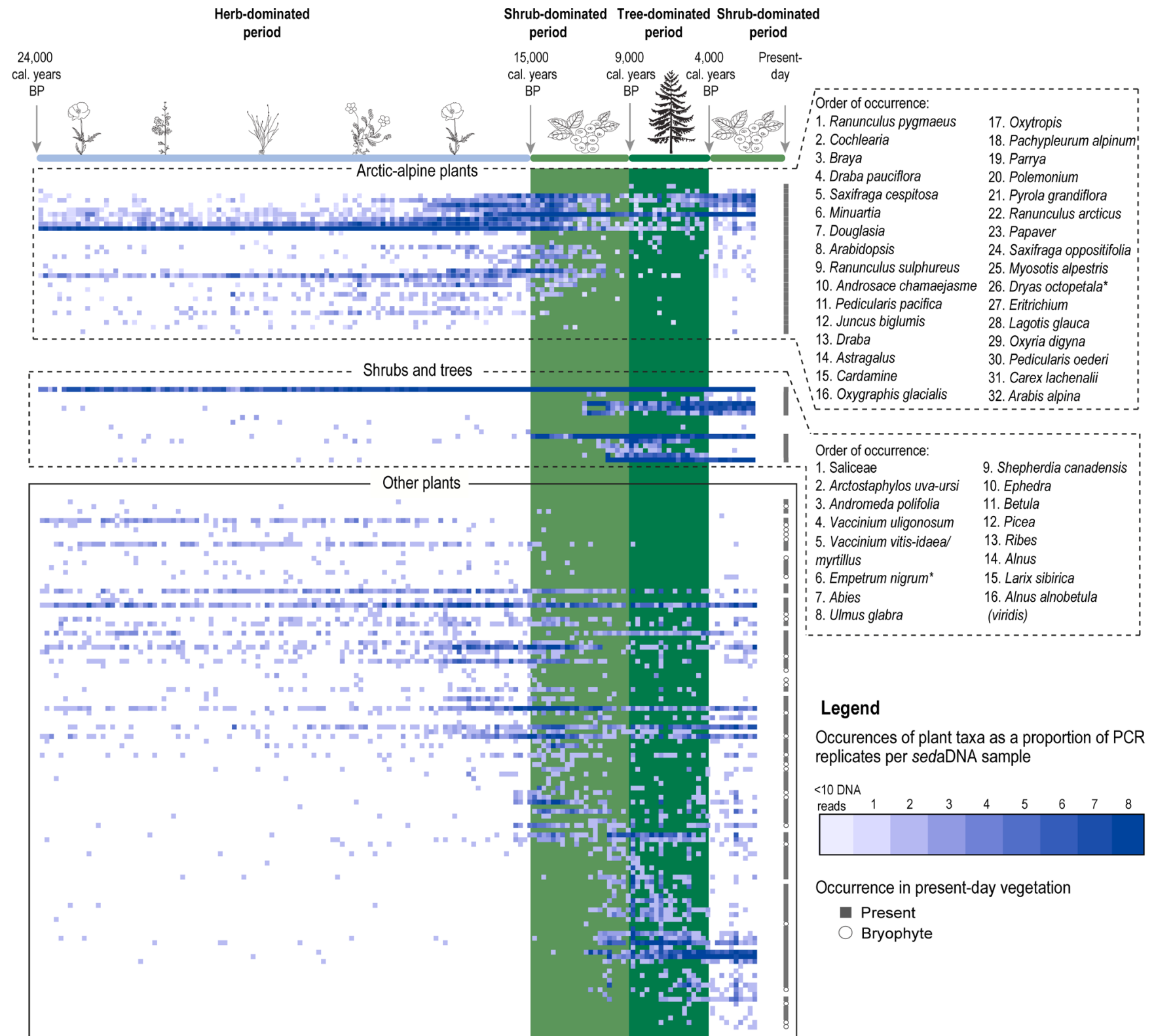

Figure 2: The ancient sediment DNA record from Lake Bolshoye Shchuchye shows the survival of arctic-alpine plants during a period when the climate was warmer, and shrubs (light green shaded bar) and trees (dark green shaded bar) expanded (modified from Clarke et al. 2019). Each square represents one occurrence of the plant taxon, with a blue color ramp used to indicate how many of the eight replicates per sample the taxon was detected within.

a period of forested conditions between 9,000 and 4,000 cal. years BP, when summer temperatures were likely warmer than present. The diversity and abundance of arctic-alpines did, however, decline as soon as shrubs expanded, suggesting that in a future warming scenario, loss of competitionsensitive arctic-alpine species may occur long before the establishment of boreal forest. Nevertheless, most of the plants that were present during the last glacial period, including all of the arctic-alpine plants, are still found in the region today, suggesting resilience to climate changes.

The Lake Bolshoye Shchuchye record highlights the conservation significance of spatially heterogeneous mountain landscapes such as the Polar Urals. Plants adapted to extreme conditions can be at high risk from climate change; arctic-alpine plants, in particular, could "run out of space" as they are out-competed by expansion of woody vegetation. However, heterogenous landscapes may provide a range of habitats for different taxa and a variety of communities.
This in turn confers resilience in the face of climate change.

\section{Future perspectives}

As more sites are analyzed for ancient DNA, we can greatly increase our knowledge of the past distribution of arctic-alpine plants. This will allow us to more effectively combine studies of modern DNA with ancient DNA records to determine past species' distributions and model likely future ones. Direct analyses of genotypes through time and space are now possible, allowing for the study of the genetic consequences of climate change (e.g. as applied to macrofossils of silver fir, Abies alba; Schmid et al. 2017). In the near future, similar studies based on ancient sedimentary DNA alone should be possible and potentially more widely applicable.

\section{AFFILIATIONS}

'Tromsø University Museum, The Arctic University of Norway (UiT), Norway

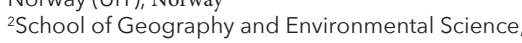
University of Southampton, UK

\section{CONTACT}

Inger G. Alsos: inger.g.alsos@uit.no

\section{REFERENCES}

Alsos IG et al. (2012) Proc R Soc Lond B 279: 2042-2051 Alsos IG et al. (2018) PLoS ONE 13: e0195403 Alsos IG et al. (2016) Holocene 26: 627-642

\section{Alsos IG et al. (2015)AoB Plants 7}

Avise JC (2000) Phylogeography: The History and

Formation of Species, Harvard University Press, $464 \mathrm{pp}$

Binney HA et al. (2009) Quat Sci Rev 28: 2445-2464 Birks, H.H. (2008) Plant Ecol Divers 1: 135-146 Brochmann Cet al. (2003) Taxon 52: 417-450 Clarke Cet al. (2019) Sci Rep 9: 19613

Eidesen PB et al. (2013) New Phytol 200: 898-910

Parducci L et al. (2017) New Phytol 214: 924-942

Pellissier L et al. (2016) J Biogeogr 43: 461-470 Schmid S et al. (2017) Methods Ecol Evol 8: 1374-1388 Sjögren P et al. (2017) New Phytol 213: 929-941 Westergaard KB et al. (2019) Mol Ecol 28: 818-832 Willerslev E et al. (2014) Nature 506: 47-51 